\title{
Palabras de Ramón Gutiérrez al recibir en la legislatura el título De ciudadano ilustre de Buenos Aires
}

Ramón Gutiérrez Acceptance of the 2011 Distinguished Citizen o Buenos Aires Award,

\section{Autor}

Ramón Gutiérrez

Debo comenzar agradeciendo a quienes hacen este reconocimiento a una trayectoria enfatizando que más allá de lo personal uno es uno y sus circunstancias, circunstancias a las que debo casi todo lo realizado. Estas mismas circunstancias definieron hoy providencialmente, que este acto se realice en el Salón "Montevideo", en un implícito homenaje a mi madre uruguaya y a mi filiación rioplatense, y que utilicemos el otro Salón adyacente denominado "Arturo Jauretche" amigo con quien compartimos tertulias memorables y con quien aprendí lo que significa la sabiduría adquirida en la propia experiencia vivida.

Este año cumplo 10 años de vida, luego del infarto que tuve en el 2001. Dios decidió darme otro trecho de vida y me ayudó a repensar, una vez más, aquellas cosas a las cuales había que privilegiar. Siempre he preferido Hacer antes que Estar, por eso cuando tuve que estar en alguna responsabilidad mi objetivo siguió siendo el Hacer. Ser Ciudadano es coherente con mi manera de pensar. Graciela, mi esposa, siempre dijo que yo era parte del "hollín y la cuadrícula". Pero mucho más que de lo urbano lo soy, si lo tomo filosóficamente como buen discípulo de Maritain y Mounier, en la medida que me considero un Personalista. Es decir que asumo mi responsabilidad en la cual como individuo adquiero mi dimensión y compromiso social y por ende me transformo en Persona. Una Persona que atiende a su inserción en la Sociedad y se preocupa y ocupa por el Bien Común.

Ahora recibo el honor de ser considerado Ciudadano de Buenos Aires, una Ciudad donde he nacido, pero donde he vivido menos de la mitad de mi vida. Llevo a cuestas casi quince años de rosarino y otros casi treinta años de vivir en Resistencia. Ello me ha ayudado a ser un porteño "vacunado", capaz de mirar mi ciudad con distancias y contextos diferentes. Me fui y volví, me fui sin poder opinar cuando tenía cinco años y volví a estudiar arquitectura en uno de los mejores momentos de la Universidad de Buenos Aires entre 1958 y 1963. Luego los "bastones largos" de una de nuestras tantas dictaduras nos alejaron de nuestra Universidad y decidimos comenzar de nuevo a 1000 kilómetros en un Chaco abierto y receptivo.

Me despidió un amigo porteño que me dijo: "Allá te ahorrás ese $70 \%$ de tiempo que tenés que dedicar aquí a andar esquivando zancadillas y el otro $30 \%$ que tenés que dedicarte vos a poner la pata". No fue tan así, pero algo de eso hay. Cuando volví treinta años después comprobé que aquí la guillotina horizontal trabajaba intensamente y que lo mejor era no asomar la cabeza, o tratar de hacerlo cuando la máquina miraba para otro lado.

El interior era más dúctil, una plastilina a la cual se le podía dar forma y donde todo estaba por hacer. Tuvimos suerte con Graciela. Nos ocupábamos de las cosas viejas, 
en un lugar donde no había "cosas viejas" por lo que las zancadillas se redujeron bastante y se limitaron al medio universitario, un lugar donde la planta de la mezquindad suele florecer casi espontáneamente y donde el trabajar ponía en evidencia las falencias de otros. Nos tocó, eso sí, una Universidad intervenida durante 17 años, donde luego de varios concursos estuvimos alternativamente un tiempo vitalicios y otros "en comisión" y donde con nuestro recordado amigo Dick Alexander montamos una irónica cartelera con frases célebres como "El silencio es salud" o "Aquí nadie dice nada" o "Lo mejor ahora es callar", que habíamos recortado de los titulares de los diarios de la época... No le hicimos mucho caso a estas recomendaciones, pero sobrevivimos, que no fue poco.

Nuestro escenario fue primero la región, luego el NOA y finalmente derrapamos hacia los países limítrofes. Pudimos hacer mucho con entusiasmo y esfuerzo. Hicimos amigos en todo el país y armamos equipos que se renuevan y permanecen en décadas de alegrías y sueños compartidos. Descubrimos que nuestra historia y nuestro patrimonio se prolongaban más allá del mundo colonial. Una beca externa del CONICET nos permitió en 1970 mirar América desde la perspectiva académica española. Ello nos ayudó a entender los variados aspectos de la transculturación y nos posibilitó una red de relaciones intelectuales y de amistad que no solamente perduran sino que nos han posibilitado continuar tareas académicas y de investigación conjunta.

Nuestra vinculación definitiva al CONICET ayudaría a definir una vocación que me ha sido motivadora en estas cuatro últimas décadas.

Fuimos y somos críticos con una Argentina que no era integradora sino excluyente, en miradas que se ejercían hacia adentro y hacia fuera. Decidimos entonces comenzar a mirar la arquitectura de nuestras provincias y a redactar los primeros libros de muchos temas del siglo XIX y XX. Nos propusimos investigar sobre lo que no se había escrito, cubrir los temas sumidos en el anonimato, proyectar lo patrimonial desde lo histórico hacia lo cultural, de lo cultural a lo social, de lo social al patrimonio construido. Del Monumento al Conjunto, del Conjunto al Poblado, del Poblado al Centro Histórico y de allí al Paisaje Cultural, a los Itinerarios y al Territorio, para mencionar simplemente todo lo que nos queda pendiente de hacer en nuestro país y en el continente.

En aquellos tiempos de vacaciones de democracia y de dudosa sobrevivencia, nos radicamos en el Perú trabajando en el Cusco para la UNESCO, en el dictado de los Cursos internacionales de Patrimonio. Fue ésta una de las mayores experiencias vitales que pudimos abordar. Decirles que nos cambió la manera de mirar la vida, asumir los valores de la relación del hombre con su paisaje y con su comunidad.

Entender el tiempo histórico de una manera diferente y el sentido de pertenencia a la cultura y al medio donde la continuidad de los siglos y los hombres señalan ese sentido sacral que tiene el vivir y el sobrevivir. Aquel mundo nos dio un nuevo horizonte y nos comprometió firmemente con la tarea pendiente de reconstruir la Patria Grande continental. 
Así el espacio de acción se amplió a nuestra América y a tratar de zurcir la urdimbre de unas culturas fragmentadas, incapaces de superar el aislamiento. Sigue siendo nuestro drama la imposibilidad de conseguir un libro del país vecino y la costumbre de seguir pensando que lo que nos sucede, nos pasa solamente a nosotros. Hoy con los nuevos sistemas de comunicación estamos más alertas y tenemos más acceso, pero nos cuesta mucho construir con la dinámica necesaria para fortalecer los lazos.

Ésa ha sido la tarea troncal de los últimos años. Primero el Instituto Argentino de Investigaciones de Historia de la Arquitectura y el Urbanismo (1978) que nos permitía contener a muchos colegas y amigos que estaban excluidos de las universidades, luego los Seminarios de Arquitectura Latinoamericana (los SAL) desde 1985, posteriormente las Bienales Iberoamericanas de Arquitectura desde 1988 y finalmente el Centro de Documentación de Arquitectura Latinoamericana (CEDODAL) desde 1995. Así se formó una vasta red de equipos que desde los distintos rincones del país y desde los extremos del continente de México a la Patagonia, fueron consolidando nuevas instancias creadoras para valorar nuestra arquitectura y nuestro patrimonio.

Buenos Aires fue tema de nuestras reflexiones insertada, con sus peculiaridades, en ese contexto americano en el cual solía plantear disonancias y admiraciones. Muchas veces he señalado nuestros dobles discursos porteños del legítimo orgullo por nuestra ciudad cuando estamos fuera de ella y el descuidado comportamiento que tenemos con sus valores cuando vivimos en ella. También la admiración que se tiene por lo que se hace en otras ciudades del primer mundo y la incapacidad para replicarlas en actitudes que puedan limitar nuestros intereses particulares. El bien común está muchas veces ausente, a pesar de los entrañables lazos de solidaridad que florecen en diversos barrios de nuestra ciudad.

Ya se había percatado de esto Laín Entralgo en 1949 cuando decía "Al porteño le gusta Buenos Aires, aunque con plena seguridad nos declare que casi todas las partes de la ciudad, tomadas una a una, le parecen feas o miméticas. Tal vez sea más preciso decir que al porteño le gusta SER de Buenos Aires". Sentimos ternura y poesía nostálgica por lo que fue nuestro pasado perdido, el de un Buenos Aires mítico que debería compatibilizarse con el sueño de la ciudad futura. Vivimos, sin embargo, esa ciudad real que derriba la memoria de los afectos pasados esperando que renazcan en su hipotético porvenir. Así, nos educaron en un pasado glorioso y nos prometieron un futuro venturoso evadiendo muchas veces explicaciones sobre el presente duro y contradictorio que nos ha tocado vivir.

Escribí sobre la historia urbana de Buenos Aires en el contexto de las miradas sociales y culturales que fueron configurando su escenario. Señalé que los habitantes de la ciudad apostábamos fuertemente desde el siglo XIX al futuro y veíamos la transformación urbana de la ciudad a partir de lo que debía ser, despreciando muchas veces lo que se era. Nos equivocábamos. De allí que no nos quede ninguna vivienda íntegra de los primeros 250 años de vida de la ciudad, que no podamos explicar con ejemplos claros algunas de las tipologías que desarrollamos y que hayamos demolido obras que hoy podemos lamentar no haber conservado. Descaracterizamos nuestro Centro Histórico y valoramos a nuestra arquitectura por supuestos valores artísticos y 
estéticos, desprendiéndolos de otros auténticos valores del patrimonio inmaterial que son parte del alma vital de Buenos Aires.

Un Buenos Aires que no solamente existe en esos testimonios tangibles sino también en la mítica tradición de su literatura, en la resonancia memoriosa de las letras de los tangos y en las versiones orales que arrancan emociones en un vecindario que atesora recuerdos y fantasías. Buenos Aires es un Paisaje Cultural con el río que nos están volviendo a tapar los especuladores inmobiliarios con sus torres de lo que llaman ahora "El real estate", con el Riachuelo contaminado cuyas orillas los antecesores de esos mismos especuladores ofrecían lotear para hacer deportes náuticos y con barrios cuyos vecinos tratan de defender de unos personajes que con el cuento de hacernos "modernos" nos van destruyendo la calidad de vida.

Nuestro Buenos Aires tiene hoy, dentro de la avenida General Paz la misma cantidad de habitantes que teníamos en 1947, no llegamos a los cuatro millones, sin embargo hemos duplicado la superficie construida. Hay más de un $20 \%$ de unidades de habitación vacías, mientras nos explican que el "Mercado" actúa en correspondencia con la demanda. Debemos decir que no es cierto, que el mercado está actuando en correspondencia con la especulación, la demanda de vivienda existe, las viviendas vacías existen, nada más que sus precios y financiamientos no están al alcance de quienes las necesitan.

Nuestro desafío es pensar la ciudad desde su propia realidad y trasformarla en atención al bien común. Entender que el espacio público es el espacio de todos y no la tierra de nadie, descuidada y sin compromiso alguno. Queremos una ciudad para vivir mejor en ella, no un mero escenario de los negocios privados hechos con el beneplácito y la complicidad de lo público. Como decía el filósofo español Aranguren, el "negocio" es etimológicamente la negación del ocio, entendido como un ocio creador y de disfrute de la vida. Una ciudad mejor lo será cuando nosotros como ciudadanos antepongamos el bien común a la satisfacción de nuestros intereses privados. Es una tarea que implica conducta cívica y una justa valoración de la ciudad que tenemos.

Hoy mi ciudad me reconoce como Ciudadano, lo de ilustre es un adjetivo demasiado fuerte para mi manera de entender la vida. Hace años cuando el Fondo Nacional de la Artes me reconoció por las investigaciones en el campo de la arquitectura dije lo que todavía pienso de mi tarea. Michel Quoist en sus "Oraciones para rezar por la calle" recordaba al ladrillo y decía que el ladrillo del cimiento es el que no se ve habitualmente, pero ese ladrillo es también el que permite que luzca otro ladrillo en la fachada. Siempre pensé que mi lugar era el ladrillo del cimiento, el que ayuda a construir, el que trata de que el muro de nuestra cultura no olvide sus raíces sumergidas, el que permitirá que otros puedan estar en la fachada cuando seamos capaces de ofrecer mejores respuestas a nuestras carencias sociales y potenciemos nuestros valores culturales.

La vida me ha permitido tener lugares desde donde he podido servir de "Puente" entre muchos amigos y colegas. Coherentemente en la creación de estas redes estaba la esperanza de una construcción superadora de aislamientos y que, mediante los 
contactos, aprendiésemos mejor a trabajar en equipo, aun a la distancia. Era lo que habitualmente hacía con los 1000 kilómetros que mediaban desde Resistencia a Buenos Aires con grandes amigos, hoy definitivamente ausentes, como Alberto de Paula, Federico Ortiz, Marina Waisman y Jorge Enrique Hardoy entre otros. Trabajar en equipo ha sido la clave de lo que hemos podido hacer y algunos de los que siguen cerca nuestro llevan más de treinta años compartiendo iniciativas, investigaciones, fatigas y alegrías. Agradezco siempre la paciencia y comprensión que conmigo han tenido.

Hoy, en el ocaso de la vida, a la que como dijo Amado Nervo nada le debo y con ella estoy en paz, lo que nos queda son los equipos que he ayudado a armar: en primer lugar mi familia con Graciela y mis hijos Martín, Rodrigo y Alejo, mis solidarios hermanos y mis compañeros cotidianos del CEDODAL, encabezados por Patricia Méndez que me acompañan en ideas y entusiasmos. Además la extensa legión de amigos y colaboradores de España y América que aceptan con un afectuoso sentido de pertenencia nuestros proyectos. Su presencia solidaria me lleva a agradecer nuevamente a Dios esta última década de vida que me ha regalado y que me permite hoy estar junto a ustedes y sentirme siempre profundamente acompañado e ilusionado con seguir el sendero que hace años la vida me ha ayudado a trazar haciendo, como diría Machado, camino al andar....

Arquitecto Ramón Gutiérrez Buenos Aires, 29 de Agosto de 2011 